\title{
Adsorptive Immobilization of Acetylcholine Esterase on Octadecyl Substituted Porous Silica: Optical Bio-analysis of Carbaryl
}

\author{
Amir Norouzy, ${ }^{\dagger, \downarrow}$ Mehran Habibi-Rezaei, ${ }^{\ddagger}, *$ Durdi Qujeq, ${ }^{\dagger}$ Maryam Vatani, ${ }^{\ddagger}$ and Alireza Badiei ${ }^{\S}$ \\ ${ }^{\dagger}$ Department of Biochemistry and Biophysics, Babol University of Medical Sciences \\ ${ }^{\star}$ School of Biology, College of Science, University of Tehran, Iran. ${ }^{*}$-mail: mhabibi@khayam.ut.ac.ir \\ ${ }^{\$}$ School of Chemistry, College of Science, University of Tehran, Iran \\ Received June 24, 2009, Accepted December 1, 2009
}

\begin{abstract}
A sensory element against carbaryl, as a widely used pesticide was prepared based on adsorbed acetylcholine esterase (AChE) from Torpedo california. Octadecyl was substituted on macro-porous silica, confirmed by infra-red (IR) spectroscopy and quantitatively estimated through thermo-gravimetric analysis (TGA). Immobilization of the enzyme was achieved by adsorption on this support. Activity of the immobilization product was measured as a function of the loaded enzyme concentration, and maximum binding capacity of the support was estimated to be $43.18 \mathrm{nmol} \cdot \mathrm{mg}^{-1}$. The immobilized preparations were stable for more than two months at storage conditions and showed consistency in continuous operations. Possible application of the immobilized AChE for quantitative analysis of carbaryl is proposed in this study.
\end{abstract}

Key Words: Bio-analysis, Acetylcholine esterase, Adsorption, Macro-porous silica, Carbaryl

\section{Introduction}

Considerable attentions have been paid to research on acetylcholine esterase-based biosensors to detect organophosphates and carbamate residues in various samples. ${ }^{1-5}$ Acetylcholine esterase (AChE, EC 3.1.1.7), hydrolyzes the neurotransmitter acetylcholine to stop nervous impulse transmission at the cholinergic synapses. Over the last decades, cholinesterase-basedbiosensors have emerged as a sensitive and rapid technique for toxicity analysis in environmental monitoring, as well as quality control of food products. ${ }^{6}$ Carbamates which act as AChE inhibitors are among the most employed insecticides in agriculture. Carbaryl (1-naphthol $N$-methylcarbamate) as a wide-spectrum carbamate insecticide has been reported to be effective against more than 100 species of insects (Fig. 1). It acts as a competitive inhibitor of AChE. ${ }^{7,8}$ Intensive use of this insecticide in agriculture has contributed significantly to environmental pollution problems and carbamate residuesin agricultural products threat human health. ${ }^{9,10}$ Moreover the human population can be exposed to carbaryl during pest control operations in residential and recreational areas. Workers are exposed to carbaryl during its manufacture, formulation, packaging, transport, and storage, during and after application.

The analysis of pesticides is usually carried out using GC or HPLC. Moreover, detection of organophosphorus and carbamate pesticides based on inhibition of the enzyme AChE hasbeen objected in numerous investigations. ${ }^{11-14}$ AChE biosensors present useful characteristics for such applications as the most selective tools for the analysis of AChE inhibitors. ${ }^{6,15}$ Most of the constructed $\mathrm{AChE}$ biosensors are based on potentiometric methods which can detect the presence of the analyte according to the changes in $\mathrm{pH}$ or redox potential in the enzymatic layer. The stable attachment of the enzyme onto the surface is the most important step for the construction of a reliable biosensor. There are many methods for immobilization of cholinesterase enzymes, such as covalent coupling, ${ }^{16,17}$ self-assembled mono-

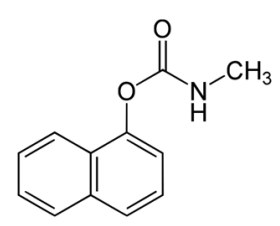

Figure 1. Structure of carbaryl (1-naphthyl methylcarbamate; $\mathrm{C}_{12} \mathrm{H}_{11}$ $\mathrm{NO}_{2}$ ), as a carbamate which is used chiefly as an insecticide.

layers (SAM) ${ }^{18,19}$ physical entrapment, ${ }^{20,21}$ and physical adsorption. $^{22,23}$ Physical adsorption is the easiest and the least denaturing method. However most biosensors produced through the adsorbed enzyme strategy suffer poor operational consistency and storage stability. ${ }^{6}$

In this work we report the virtually irreversible binding of $\mathrm{AChE}$ on alkyl substituted micro porous silica to construct AChE-based biosensor for detection and quantification of carbaryl. The designed sensory device was confirmed to exhibit storage and operational stability. The sensitivity and linear function of the constructed biosensor against the concentration of carbaryl have been documented.

\section{Materials and Methods}

Acetylthiocholine iodide, DTNB [5,5-Dithiobis (2-Nitrobenzoic acid)], and acetylcholine esterase from Torpedo california (electric eel) were purchased from SIGMA, (St. Louis, MO, USA). Carbaryl (Sevin; 1-naphthol $N$-methylcarbamate) was provided by the Managing Center of Applied Studies and Quality Control, Ministry of Agriculture, Karaj-Iran. Macroporous silica, trichlorooctadecylsilane, toluene, calcium chloride and dioxane were purchased from Merck (Darmstadt, FRG).

Alkylation of macro-porous silica. $150 \mathrm{~mL}$ toluene was dried by agitating with $30 \mathrm{~g}$ anhydrous calcium chloride overnight, followed by distillation. Macro-porous silica with an average 
(a)

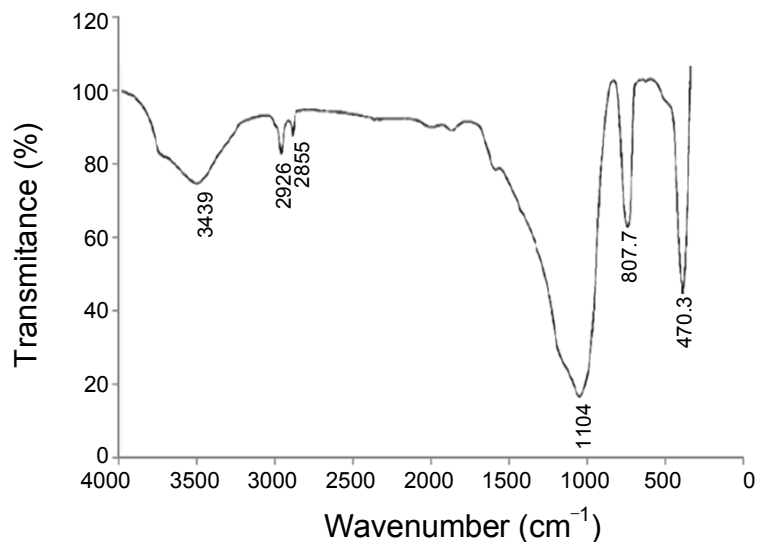

(b)

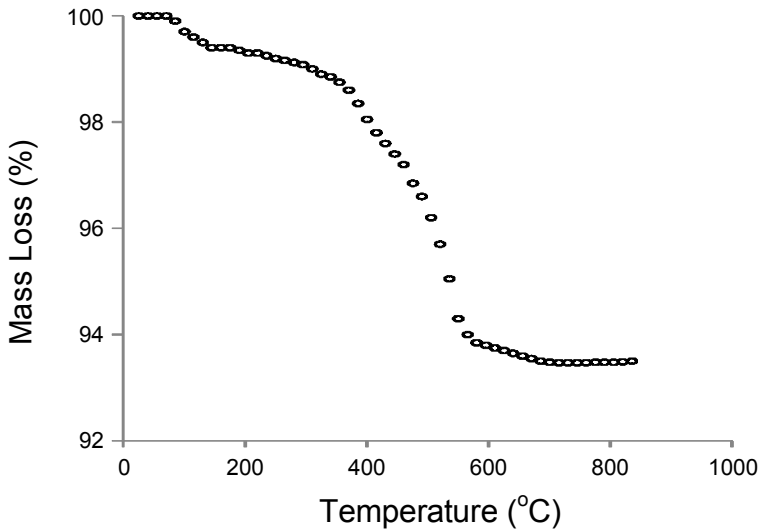

Figure 2. (a) Infrared spectrum of the alkylation product as attached octadecyl substituted on macro-porous silica. (b) Mass loss as a function of temperature (TGA analysis) of octadecyl substituted macro porous silica.

pore size of $60 \mathrm{~nm}$ was dried under vacuum. Trichloro-octadecylsilane was dissolved in dried toluene and added to dry matrix. Alkylation was achieved by refluxing overnight. The attachment of the octadecyl moieties on macro-porous silica was approved using FTIR spectrophotometer (Equinox 55, Bruker). IR spectra were recorded in the range $4000-400 \mathrm{~cm}^{-1}$, using $\mathrm{KBr}$ pellets. Spectra were calculated from a total of 18 scans (Fig. 2a). The mole number of alkyls per gram of macro-porous silica was calculated by thermogravimetric analysis (TGA) which was performed on a TA instrument Q50 (Fig. 2b).

Immobilization of AChE. 20 mg octadecyl-substituted macro-porous silica as carrier was washed twice with $300 \mu \mathrm{L}$ of $50 \mathrm{mM}$ phosphate buffer, $\mathrm{pH} 7.4$, then was loaded with $300 \mu \mathrm{L}$ of AChE at concentration range of $0-0.2 \mathrm{mg} \cdot \mathrm{mL}^{-1}$ in the same buffer. The mixtures were then incubated for $90 \mathrm{~min}$ at room temperature under gentle rotary stirring. Assessment of immobilization was carried out through estimation of protein and AChE activities in the supernatants after 5 min centrifugation at $3000 \times$ g. Pellets were washed thrice with $1 \mathrm{~mL}$ buffer solution to ensure removal of the trapped or non-bound enzyme molecules from the adsorption product. The support bearing the immobilized AChE was used to directly assess the immobilization process and to perform discontinuous and continuous catalytic transformations in the forms of batch or packed bed reactors, respectively.

Enzyme assay. Soluble AChE was assayed according to the method of Ellman. ${ }^{24}$ The assay mixture contained acetylthiocholine iodide at $500 \mu \mathrm{M}$ in Ellman reagent. The Ellman reagent contained $9.1 \mathrm{mg}$ DTNB, $3.75 \mathrm{mg}$ sodium bicarbonate in 100 $\mathrm{mL}$ phosphate buffer ( $25 \mathrm{mM}, \mathrm{pH} 7.4)$. The enzymatic reaction was monitored at $412 \mathrm{~nm}$ using a Camspect M550 double beam spectrophotometer. Activity of the immobilized AChE was determined directly on the immobilized preparations $1 \mathrm{~mL}$ Ellman reagent was added to $1.8 \mathrm{mg}$ immobilized $\mathrm{AChE}$. The reaction mixture was incubated at room temperature for desired time periods under gentle stirring. Then reaction was terminated by removing the immobilization product using centrifugation at $500 \mathrm{rpm}$ for 10 seconds. To assess the immobilized enzyme activity, the absorbance of supernatant was read out at $412 \mathrm{~nm}$. The inhibitory effect of carbaryl on AChE reaction was studied by adding carbaryl at the concentration range of $0-700 \mu \mathrm{M}$.

Stability of the immobilized preparation. Immobilization products were considered for their functional stability at storage conditions $\left(4^{\circ} \mathrm{C}\right.$ and $25^{\circ} \mathrm{C}$, in $50 \mathrm{mM}$ phosphate buffer solution, $\mathrm{pH} 7.4$ ), up to 70 days. The esterase activity of the immobilized $\mathrm{AChE}$ on octadecyl-substituted porous-silica was monitored at one day intervals. The batch of the preparation was pre-washed with the same buffer followed by direct assay as mentioned above. After each measurement, the preparations were washed again by phosphate buffer solution $(50 \mathrm{mM}, \mathrm{pH} 7.4)$ followed by vortexing and restored at defined conditions until the next round of measurements. Each series of measurements were carried out twice for duplicate samples and the mean activities were considered.

Inhibition of continuous catalytic transformation by carbaryl. Batch mode analysis of the inhibitory effect of carbaryl on catalytic transformation of acetylthiocholine was carried out using $20 \mathrm{mg}$ immobilization product and $10 \mu \mathrm{L}$ carbaryl in dioxan at various concentrations. The continuous catalytic transformation of acetylthiocholine by adsorbed $\mathrm{AChE}$ and its inhibition by a carbamate member carbaryl were performed (Fig. 3a). The sandwich of $20 \mathrm{mg}$ of immobilized AChE preparation was placed between two layers of $37 \mathrm{mg}$ of non-loaded matrix, in a glass column with an internal diameter of $0.7 \mathrm{~cm}$ to make a disposable assay cartridge. Mentioned configuration was then located in the circuit after a T-shaped connector equipped with a silicon septum in the flow path (Fig. 3b). The assay cocktail including the substrate acetylthiocholine, was pumped through the column at $200 \mu \mathrm{L} \cdot \mathrm{min}^{-1}$. Absorbance of the column effluent was recorded at $412 \mathrm{~nm}$ against blank sample. Due to labiality of the substrate solution, continuous catalytic operations were carried out at $4{ }^{\circ} \mathrm{C}$. The configuration was used to detect the presence of carbaryl as analyte. For each analysis, $50 \mu \mathrm{L}$ of sample containing carbaryl in dioxan was injected to the flow path through the silicon septum of the configured system. The final concentration of carbaryl in the reaction vessel was adjusted to the range of $0-400 \mathrm{ppm}$. The slopes of resulted curves represent the inactivation rate constants as $k_{i}$ (at percent per minute) were determined in linear regions. The system was recharged for the next analytical run by replacement of the packed immobilized AChE cartridges (Fig. 3b). 
(a)

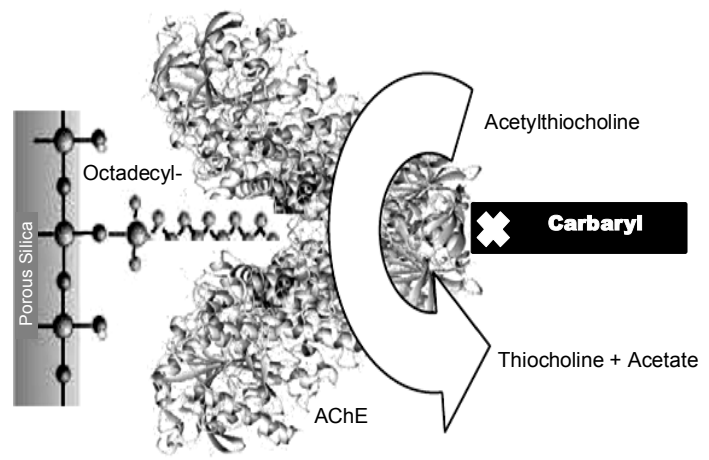

(b)

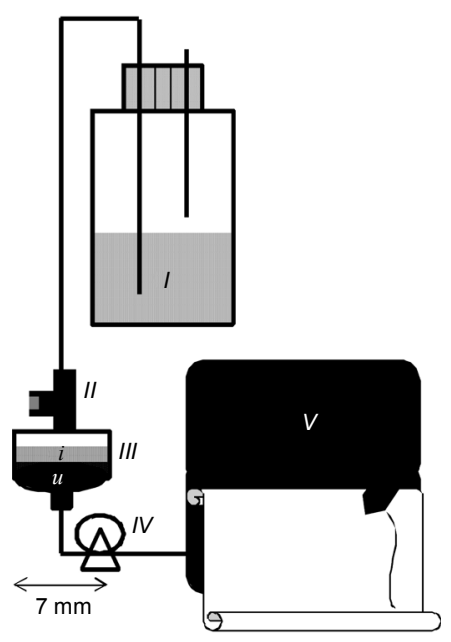

Figure 3. Schematic representation of (a) inhibitory effect of carbaryl (as a carbamate insectisde) on immobilized acetylcholine esterase (AChE) on octadecyl substituted porous silica, (b) the constructed optical biosensor based on immobilized $\mathrm{AChE}$ on octadecyl substitutes porous-silica: I. reservoir, II. T-shaped connector, III. bio-reactor (holding immobilized-AChE preparation $(i)$ covered by a layer of porous silica (ii), $I V$. pump and $V$. visible spectrophotometer/recorder. Steady flow rate of the reaction cocktail was adjusted at $200 \mu \mathrm{L} \cdot \mathrm{min}^{-1}$. Carbaryl was injected through a silicon septum equipped at T-shaped connector. Post-column analysis was carried out at $412 \mathrm{~nm}$.

\section{Results and Discussion}

Standard methods for analysis of pesticides include sample pretreatment and determination by GC or HPLC. ${ }^{25}$ As a result, these methods of analysis are expensive and have limited sample capacities. In this study, we report an optical biosensor for flow injection analysis of carbamate pesticide residue based on the degree of inhibition of AChE. In the view of strength of immobilizing linkage, the covalent coupling of AChE is the most widely used method of $\mathrm{AChE}$ immobilization for use in biosensors. ${ }^{26}$ However here we are reporting the adsorptive immobilization of AChE on octadecyl substituted inorganic porous silica as an efficient alternative to covalent coupling. Macro-porous silica was alkylated by trichlorooctadecylsilane and attachment of octadecyl substitutes on the macro-porous silica was approved by IR spectroscopy (Fig 2a). As depicted in the figure, the only functional groups detected are methyl and methylene as illustrated by the IR spectra of alkylated macro-porous silica. The IR spectrum exhibits weak bands at 2855 and 2926 $\mathrm{cm}^{-1}$ and a broad band at $1104 \mathrm{~cm}^{-1}$ which relates to a stretched

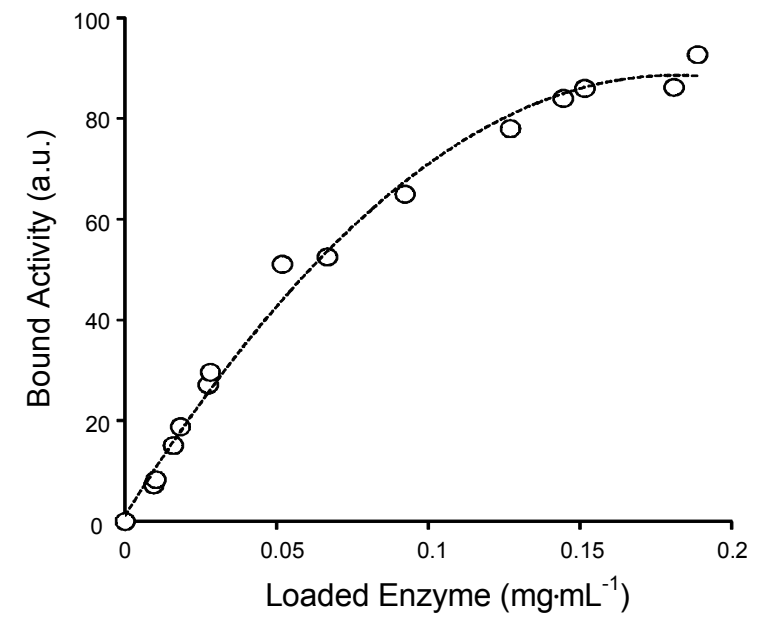

Figure 4. Saturation plot of AChE binding on octadecyl substituted porous silica. Data are presented based on the immobilized activity (after indirect assay) as a function of the loaded enzyme concentrations. For each estimation, $20 \mathrm{mg}$ octadecyl-substituted macro-porous silica, as carrier was used after washing twice with $300 \mu \mathrm{L}$ of $50 \mathrm{mM}$ phosphate buffer, $\mathrm{pH} 7.4$, followed by $90 \mathrm{~min}$ incubation in the presence of $300 \mu \mathrm{L}$ of $\mathrm{AChE}$ at concentration range of $0-0.2 \mathrm{mg} \cdot \mathrm{mL}^{-1}$ in the same buffer. Each series of measurements were carried out thrice for duplicate samples and the mean activities were considered.

$\mathrm{C}-\mathrm{H}$ bond and a waging $\mathrm{C}-\mathrm{H}$ bond, respectively, with $\mathrm{SP}^{3}$ carbon hybridization. The weak and broad band at $3439 \mathrm{~cm}^{-1}$ is for stretching vibrations of the $\mathrm{O}-\mathrm{H}$ bonds of water adsorbed inevitably from air. Sharp bands at 807.7 and 470.3 are due to bending vibrations of Si-O bonds. The mole numbers of octadecyl moieties bound per gram of macro-porous silica was estimated by thermogravimetric analysis (TGA) (Fig. 2b). In this method, the temperature is increased by time, and adsorbed water evaporates about $110{ }^{\circ} \mathrm{C}$. However the organic component of the sample begins to burn at nearly $300{ }^{\circ} \mathrm{C}$. As a result, $221.2 \mu$ mols of octadecyl was bound per gram of porous silica. The maximum capacity of the support (octadecyl-substituted macro-porous silica) for holding the AChE activity was determined based on indirect assay and the resulting saturation plot has been presented in figure 4 . The maximum binding capacity of the matrix was estimated to be $2.833 \times 10^{-3} \mathrm{mg}$ (or $43.18 \mathrm{nmol}$ ) AChE per mg matrix. In the saturation state, activity per $\mathrm{mg}$ of the immobilization product was determined at $73 \mu \mathrm{mol} \cdot \mathrm{min}^{-1}$. The specific activities of the free and immobilized enzymes were $2.695 \times 10^{-3} \mu \mathrm{mol}$. $\mathrm{min}^{-1} \cdot \mathrm{mg}^{-1}$ and $25.768 \times 10^{-3} \mu \mathrm{mol} \cdot \mathrm{min}^{-1} \cdot \mathrm{mg}^{-1}$ (based on direct assessment) respectively the specific activity of the immobilized enzyme shows about ten folds increase compared to the free form. Therefore adsorptive immobilization of AChE, not only does not cause harmful effect on the enzyme activity, but also improves activity, whereas AChE sustains inactivation upon covalent immobilization. ${ }^{27}$

The storage stability of the esterase activity of immobilized AChE on octadecyl-substituted porous-silica was monitored at day intervals up to 70 days at $4{ }^{\circ} \mathrm{C}$ and room temperature $(25$ $\left.{ }^{\circ} \mathrm{C}\right)$. The immobilization products retain their activities even after three washing and vortexing steps. The remaining activities of the multi-washed and multi-used preparations after 70 days are reported to be $100 \%$ and $79 \%$ at $4{ }^{\circ} \mathrm{C}$ and $25^{\circ} \mathrm{C}$ respectively 


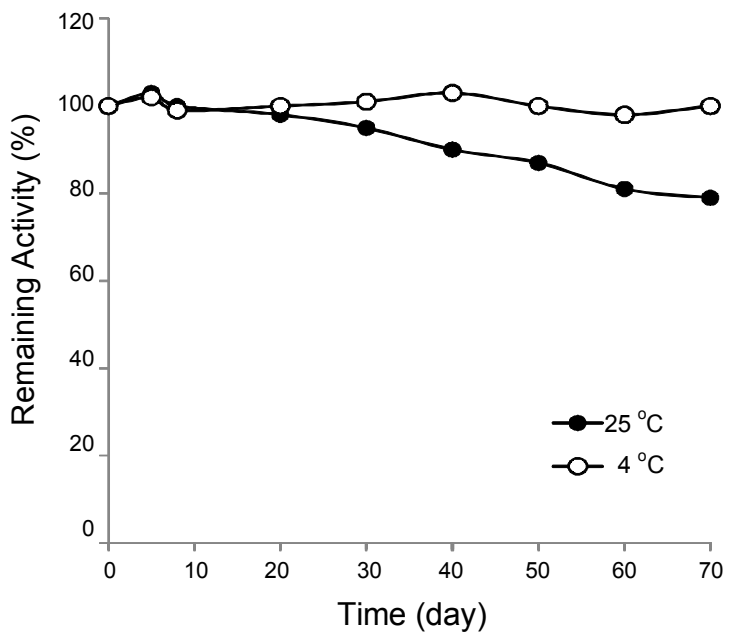

Figure 5. Catalytic stability of the immobilization product (AChE on octadecyl substituted porous silica) at $4{ }^{\circ} \mathrm{C}$ and $25^{\circ} \mathrm{C}$, in 50 $\mathrm{mM}$ phosphate buffer solution, $\mathrm{pH} 7.4$, at day intervals up to 70 days. After each assay, products were washed thrice under vortexing by phosphate buffer $50 \mathrm{mM}, \mathrm{pH} 7.4$ and stored at defined conditions until the next round of assays. Each series of measurements were carried out twice for duplicate samples and the mean activities were considered.

(Fig. 5). These observations indicate the efficiency of the simple adsorptive immobilization of AChE on octadecyl-substituted porous-silica. Continuous catalytic operation was carried out for 2 hours steadily to convert acetylthiocholine to thiocholine in a packed-bed enzyme reactor by using the configuration presented in Figure 3b. The immobilized AChE showed no decrease in activity over the period of continuous operation. This indicates that the adsorbed AChE has sufficient catalytic stability in order to be used as the sensory element in the analyte estimation system throughout of the analysis. The support was found to be reusable through washing with organic solvents such as toluene or dioxane which eliminate adsorptive interactions between the enzyme and support thereby permitting the dissociation of the enzyme and preparing the support for re-loading by new enzyme. Moreover, the support was found to be reusable after each run of continuous operation, through washing with organic solvents such as toluene or dioxane which eliminate adsorptive interactions between the enzyme and support thereby permitting the dissociation of the enzyme and preparing the support for re-loading by new enzyme. As reported earlier ${ }^{28-30}$ relatively long alkyl chains (e.g. $\mathrm{C}_{18}$ ) on the surface of porous silica used in this study, ensure efficient hydrophobic interactions to take place, making the adsorption process virtually irreversible. These kinds of strong associations are necessary to retain catalytic activity in continuous operations for the required length of time in optical bio-analysis of the carbaryl. Although warnings were made on the use of long alkyl chains for protein adsorption purposes, due to increasing the risk of denaturation $^{31,32}$ results presented here and during the last decades ${ }^{28,29,33}$ clearly demonstrate that such process of adsorption is mild and functional properties of a protein are preserved upon adsorption and the product of adsorption is stable enough in continuous (a)

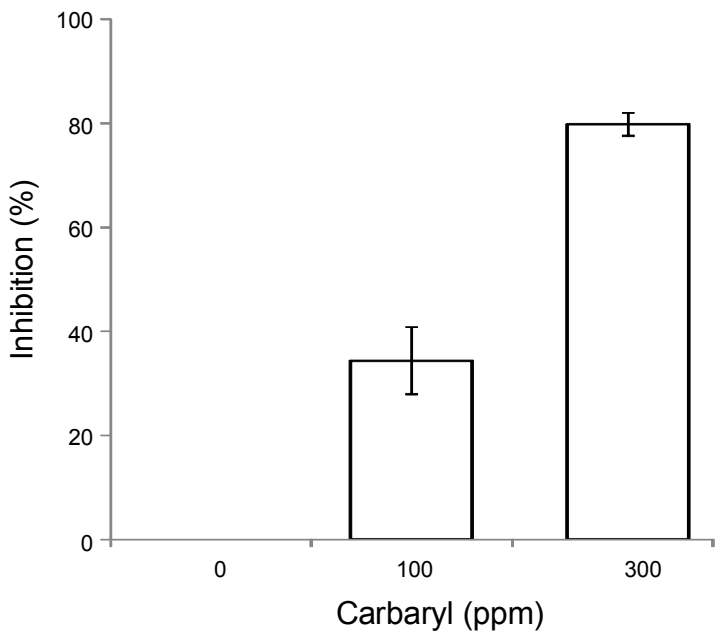

(b)

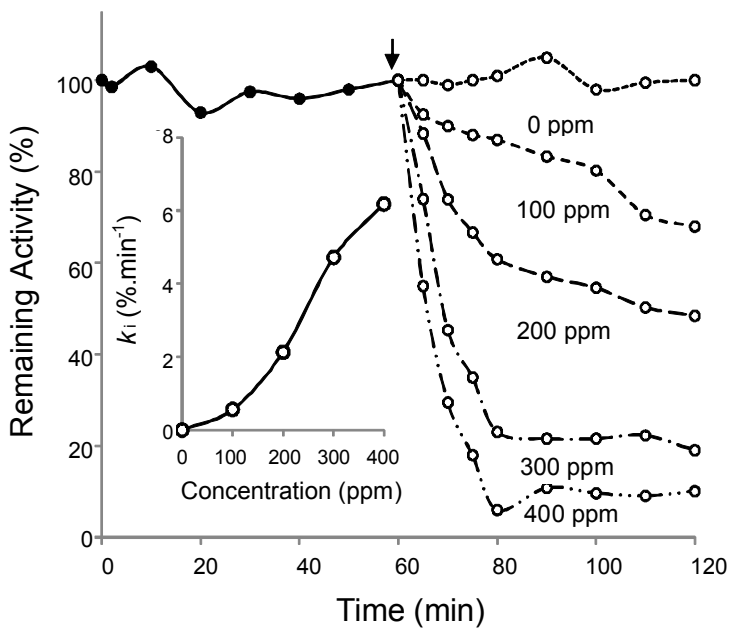

Figure 6. Analysis of the inhibitory effect of carbaryl on the activity of adsorbed AChE on octadecyl substituted porous silica; (a) in batch mode analysis; $200 \mathrm{mg}$ of immobilization product in the presence of assay cocktail were incubated at $25{ }^{\circ} \mathrm{C}$ for $20 \mathrm{~min}$ after addition of appropriate concentrations of carbaryl in Dioxan. Each concentration was assessed in thrice. (b) Responses of the immobilized AChE against carbaryl concentrations was quantified by using a continuous catalytic transformation process in a configured system at $4{ }^{\circ} \mathrm{C}$ (see Figure $2 \mathrm{~b}$ ). The constant flow rate of assay cocktail was adjusted at $200 \mu \mathrm{L} \cdot \mathrm{min}^{-1}$. The production of thiocholine was monitored using absorbance at $412 \mathrm{~nm}$ against blank sample. For each analysis, $50 \mu \mathrm{L}$ of analyte in dioxan was injected to the flow path. Arrow shows the time of injection. Inset to figure presents $\mathrm{AChE}$ inactivation rate constant as a function of carbaryl concentration.

transformations or bioanalytical applications (Fig. 6). Moreover, adsorptive immobilization of $\mathrm{AChE}$ on hydrophobized surface of porous silica ensures in-costly, re-usable/re-chargeable immobilization strategy.

Carbaryl is a wide-range carbamate insecticide and is used widely in farms. It is considered as a bio-hazardous and environmental pollutant. Moreover its remnants in agricultural food products is a threat to human health. ${ }^{1,2}$ The kinetics of AChE inhibition by carbaryl has previously been reported, ${ }^{34}$ however, the inhibitory effect of carbaryl on adsorbed AChE has been examined in this work and found to be concentration-responsive in batch mode (Fig. 6a). Such response was also observed in 
continuous catalytic transformation after injection of $50 \mu \mathrm{L}$ of the sample containing known concentrations of carbaryl to the flow path of the system (Fig. 6b). The trend of change in the slope of the sensogram is in good agreement with the administered concentrations of the pesticide in injected samples particularly at concentrations higher than $20 \mathrm{ppm}$. The satisfying linearity $\left(r^{2} \geq 0.95\right)$ indicates that the calibration curve is reliable to detect carbaryl concentration.

\section{In Conclusion}

Methods of immobilization suffer from several limitations such as leakage of the bio-component and possible diffusion barriers which restrict the performance of the biosensor. ${ }^{35}$ The simple adsorptive immobilization of AChE on octadecyl substituted porous silica was therefore found to be useful and applicable to make the AChE-based sensory element. Although, various strategies have been reported to make AChE-based biosensors, ${ }^{6,36,37}$ but effective immobilization of $\mathrm{AChE}$ on hydrophobized surface of porous silica is featured to have acceptable detection limit at $20 \mathrm{ppm}$, high storage and operational stability (figures 5 and $6 \mathrm{~b}$, respectively), well response linearity in the acceptable range of analyte concentrations (Fig. 6b), and simplicity in both of the applied strategy to prepare sensory element and the process of operation.

Acknowledgments. The authors gratefully acknowledge "New Ideas Research Institute (NIRI)". This work was funded by a grant from the Babol University of Medical Sciences and supported by the Research Council of the University of Tehran.

\section{References}

1. Nunes, G. S.; Skladal, P.; Yamanaka, H.; Barcelo, D. Analytica Chimica Acta 1998, 362, 59.

2. La Rosa, C.; Pariente, F.; Hernandez, L.; Lorenzo, E. Analytica Chimica Acta 1994, 295, 273.

3. Andrescu, S.; Avramescu, A.; Bala, C.; Magearu, V.; Marty, J. L. Anal. Bioanal.Chem. 2002, 374, 39.

4. Andreescu, S.; Barthelmebs, L.; Marty, J. L. Analytica Chimica Acta 2002, 464, 171.

5. Flores, F.; Artigas, J.; Marty, J. L.; Valdés, F. Anal. Bioanal. Chem. 2003, 376(4), 476

6. Andreescu, S.; Marty, J. L. Biomolecular Engineering 2006, 23(1), 1.

7. Blevins, R. D.; Dunn, W. C. J. Agric. Food Chem. 1975, 23(3), 377.
8. Houghton, P. J.; Rena, Y.; Howes, M. J. Nat. Prod. Rep. 2006, 23,181 .

9. Granmer, M. F. Neurotoxicology 1986, 7, 247.

10. Wills, J. H.; Jamson, E.; Coulston, F. Clinic. Toxicol. 1968, 1, 265.

9. Mavrikou, S.; Flampouri, K.; Moschopoulou, G.; Mangana, O.; Michaelides, A.; Kintzios, S. Sensors 2008, 8(4), 2818.

11. Ashok, K.; Singh, D. S. Comp. Biochem. Physiol. 1998, $119,97$.

12. Santhoshkumar, P.; Karanth, S.; Shivanandappa, T. Fundam. Appl. Toxicol. 1996, 32, 23.

13. Yazal, J. E.; Rao, S. N.; Mehl, A.; Slikker, W. J. Toxicol. Sci. 2001, $63,223$.

14. Suwansa-ard, S.; Kanatharana, P.; Asawatreratanakul, P.; Limsakul, C.; Wongkittisuksa, B.; Thavarungkul, P. Biosens. Bioelectron. $\mathbf{2 0 0 5}, 21,445$.

15. Skladal, P.; Fiala, M.; Krejci, J. Intern. J. Environ. Anal. Chem. 1996, 65, 139.

16. Kumar, J.; Kumar Jha, S.; D’Souza, S. F. Biosensors and Bioelectronics 2006, 21, 2100.

17. Lee, H. S.; Kim, Y. A.; Chao, Y. A.; Lee, Y. T. Chemosphere 2002, 46,571

18. Wink, T.; Van Zuilen, S. J.; Bult, A.; Bennekom, W. P. Analyst 1997, 122, 43R.

19. Gooding, J. J.; Hibbert, D. B. Trends Anal. Chem. 1999, 18, 525.

20. Pauliukaite, R.; Schoenleber, M.; Vadgama, P.; Brett, C. M. Biocatal. Biotransform. 2004, 22, 145.

21. Sotiropoulou, S.; Chaniotakis, N. A. Biomaterials 2005, 26, 6771.

22. Joshi, K. A.; Tang, J.; Haddon, R.; Wang, J.; Chen, W.; Mulchaldani, A. Electroanalysis 2005, 7, 54.

23. Lin, Y. H.; Lu, F.; Wang, J. Electroanalysis 2004, 16, 145.

24. Ellman, G. L.; Coutney, K. D.; Valentino, A.; Featherstone, R. M. Biochem. Pharmacol. 1961, 7, 88.

25. Sherma, J. J. Environ. Sci. Health B 2007, 42, 429.

26. Bartolini, M.; Cavrini, V.; Andrisano, V. Analytical Biochemistry 2005, 342, 163.

27. Barshan-Tashnizi, M.; Ahmadian, Sh.; Niknam, K.; Torabi, S. F.; Ranaei-Siadat, S. O. Biotechnol. Appl. Biochem. 2009, 52, 257.

28. Nemat-Gorgani, M.; Karimian, K. Eur. J. Biochem. 1982, 123, 601.

29. Habibi-Rezaei, M.; Nemat-Gorgani, M. Appl. Biochem. Biotechnol. 2002, 97, 79.

30. Duncan, A. C.; Sefton, M. V.; Brash, J. L. Biomaterials 1997, 18 , 1585.

31. Hofstee, B. H. J. Biochem. Biophys. Res. Commun. 1973, 50, 751.

32. Hjerten, S. J. Chromatogr. 1973, 87, 325.

33. Azari, F.; Hosseinkhani, S.; Nemat-Gorgani, M. Appl. Biochem. Biotechnol. 2001, 94, 265.

34. Yongnian, N.; Dongxia, C.; Serge, K. Anal. Chim. Acta 2007, 588, 131.

35. Andreescu, S.; Barthelmebs, L.; Marty, J. L. Anal. Chem. Acta 2002, 464, 171.

36. Valdés-Ramírez, G.; Cortina, M.; Ramírez-Silva, M. T.; Marty, J. L. J. Anal. Bioanal. Chem. 2008, 392, 699.

37. Abad, J. M.; Pariente, F.; Hernández, L.; Abruña, H. D.; Lorenzo, E. Anal. Chem. 1998, 70, 2848. 